\title{
PREVALENCE OF NON-ALCOHOLIC FATTY LIVER DISEASE IN HYPOTHYROIDISM IN A TERTIARY CARE HOSPITAL IN EASTERN INDIA
}

\author{
Rina Mohanty1, Samarendra Nath Das², Aujjwalya Kumar Jena ${ }^{3}$, Sarita Behera ${ }^{4}$, Nirmal Chandra Sahu ${ }^{5}$, Bijendra Mohanty ${ }^{6}$, \\ Sarada Priyadarshini Suna7, Pravat Kumar Thatoi ${ }^{8}$
}

\begin{abstract}
${ }^{1}$ Associate Professor, Department of Medicine, SCB Medical College, Cuttack. ${ }^{2}$ Associate Professor, Department of Medicine, SCB Medical College, Cuttack. ${ }^{3}$ Postgraduate Student, Department of Medicine, SCB Medical College, Cuttack. ${ }^{4}$ Assistant Professor, Department of Medicine, SCB Medical College, Cuttack. ${ }^{5}$ Assistant Professor, Department of Medicine, SCB Medical College, Cuttack. ${ }^{6}$ Postgraduate Student, Department of Medicine, SCB Medical College, Cuttack. ${ }^{7}$ Postgraduate Student, Department of Medicine, SCB Medical College, Cuttack ${ }^{8}$ Assistant Professor, Department of Medicine, SCB Medical College, Cuttack.
\end{abstract}

\section{ABSTRACT}

\section{BACKGROUND}

Thyroid hormones are involved in lipid metabolism, insulin resistance and regulation of bodyweight. There are inconclusive data regarding substantial involvement of hypothyroidism in non-alcoholic fatty liver disease (NAFLD).

The aim of this study is to evaluate the prevalence of NAFLD in hypothyroidism.

\section{MATERIALS AND METHODS}

A descriptive study was conducted in the Department of General Medicine of SCB Medical College, Cuttack and consecutively 100 adult non-obese hypothyroid patients (50 treated and 50 untreated) were included in the study, and the patients were evaluated for NAFLD using ultrasonography. The results were compared with 100 age, sex and body mass index (BMI) matched euthyroid controls.

\section{RESULTS}

From 100 hypothyroid patients, 30 NAFLD patients were detected and 12 NAFLD patients were detected in controls ( $p=0.003$ ). There was increased incidence of NAFLD in persons with high serum TSH value $(\geq 4.1 \mathrm{mIU} / \mathrm{L})$ and low free $\mathrm{T}_{4}$ value $(\leq 0.7 \mathrm{ng} / \mathrm{dL})$.

\section{CONCLUSION}

Prevalence of NAFLD in non-obese hypothyroid patients is higher in comparison to non-obese euthyroid controls, and the incidence is also high in untreated hypothyroid patients in comparison to treated hypothyroid patients.

\section{KEYWORDS}

Hypothyroidism, Insulin Resistance, Non-alcoholic Fatty Liver Disease.

HOW TO CITE THIS ARTICLE: Mohanty R, Das SN, Jena AK, et al. Prevalence of non-alcoholic fatty liver disease in hypothyroidism in a tertiary care hospital in eastern India. J. Evolution Med. Dent. Sci. 2017;6(79):5589-5593, DOI: 10.14260/jemds/2017/1213

\section{BACKGROUND}

Non-alcoholic fatty liver disease (NAFLD) includes diseases of liver ranging from simple fatty liver to non-alcoholic steatohepatitis (NASH), which if untreated may lead to cirrhosis of liver and hepatocellular carcinoma. ${ }^{1}$ It is the commonest liver disease worldwide. ${ }^{2}$ The increased prevalence of NAFLD is directly related to increased incidence of obesity, metabolic disorders such as insulin resistance, diabetes mellitus, and hypertension and dyslipidaemia. ${ }^{3}$ Since thyroid hormones are thoroughly involved in cell metabolism, energy homoeostasis, regulation of body weight, lipid and carbohydrate metabolism, and adipogenesis, 4,5 there is chance of association between thyroid dysfunction and NAFLD/NASH. There is growing data

'Financial or Other Competing Interest': None.

Submission 25-08-2017, Peer Review 19-09-2017,

Acceptance 25-09-2017, Published 30-09-2017.

Corresponding Author:

Pravat Kumar Thatoi,

Flat-104, Aryabhatta Complex,

College Square, Cuttack-753003,

Odisha, India.

E-mail: drpravatthatoi@yahoo.co.in

DOI: $10.14260 /$ jemds/2017/1213

\section{(c) (i) $(9)$}

about higher prevalence of thyroid dysfunction in the form of overt or subclinical hypothyroidism among patients with NAFLD/NASH. ${ }^{6}$ The prevalence of hypothyroidism was reported to range from $15.2 \%$ to $36.3 \%$ among patients with NAFLD/NASH. ${ }^{7}$ Several studies using healthy controls showed a significantly higher prevalence of hypothyroidism in patients with NAFLD/NASH compared to the controls. Several studies also demonstrated that hypothyroidism is an independent risk factor for NAFLD. ${ }^{6}$ This indicates that hypothyroidism may directly result in NAFLD irrespective of other metabolic risk factors. Considering the results of these studies, hypothyroidism may be added to risk factors of NAFLD/NASH. Chung et al, ${ }^{6}$ in their population based study, evaluated a relatively large number of healthy individuals and showed that prevalence of NAFLD plus elevated alanine aminotransferase (ALT) was higher in patient with hypothyroidism. An increased serum ALT level is a surrogate biomarker for NAFLD in the absence of other causes of liver disease. Therefore, this study confirms the association between the severity of NAFLD and hypothyroidism. Pagadala et $\mathrm{al}^{8}$ reported that hypothyroidism was more common in patients with NASH compared to patients with NAFLD. This finding remained statistically significant after adjusting for other variables including age, diabetes, 
dyslipidaemia and hypertension but not gender.9. The prevalence of NAFLD in hypothyroidism has not been well studied in our region. A descriptive study was conducted to highlight the prevalence of NAFLD in non-obese euthyroid patients and its association with both treated and untreated hypothyroid patients.

\section{MATERIALS AND METHODS}

This study was a descriptive study. After clearance from institutional ethics committee (IEC), we designed an observational descriptive study as per the following:

\section{Patient Selection Criteria}

Consecutively 100 adult non-obese hypothyroid patients those attended the outpatient department (OPD) or admitted to indoor department of SCB Medical College, Cuttack, were included in the study. Sample size was taken conveniently. These patients were divided into two groups, those who were under treatment for hypothyroidism in the form of L-thyroxin replacement therapy were included in treated group $(n=50)$ and those who were not under treatment were included in non-treated group $(n=50)$. The controls were age, sex and BMI matched non-obese euthyroid persons $(n=100)$.

\section{Exclusion Criteria}

Individuals with obesity, diabetes mellitus, hypertension, chronic kidney disease, underlying liver diseases such as cirrhosis, autoimmune or viral hepatitis and those with $>20$ $\mathrm{g} /$ day alcohol consumption were excluded from the study.

\section{Case Definition}

Euthyroidism was defined as a serum TSH level between 0.4 and $4.1 \mathrm{mIU} / \mathrm{L}$ with normal free $\mathrm{T}_{4}\left(\mathrm{FT}_{4}\right)$ levels (0.7-1.8 $\mathrm{ng} / \mathrm{dL}$ ). Subclinical hypothyroidism was defined as serum $\mathrm{TSH} \geq 4.1 \mathrm{mIU} / \mathrm{L}$ with normal $\mathrm{FT}_{4}$ concentration, and overt hypothyroidism was defined as serum TSH $\geq 4.1 \mathrm{mIU} / \mathrm{L}$ and $\mathrm{FT}_{4}$ level less than $0.7 \mathrm{ng} / \mathrm{dL}$.

\section{Methods}

All patients and controls were subjected to detailed history and thorough clinical examination with reference to past medical history, anthropometric assessment and laboratory tests. Height and body weight were measured and body mass index (BMI) was calculated as follows: BMI= body weight $(\mathrm{kg}) /$ height squared $\left(\mathrm{m}^{2}\right)$. The normal range of BMI is 19$24.9 \mathrm{~kg} / \mathrm{m}^{2}$, overweight is $25-29.9 \mathrm{~kg} / \mathrm{m}^{2}$, and obesity $\geq 30$ $\mathrm{kg} / \mathrm{m}^{2}$. Waist circumference was measured in millimetre at the midpoint between the lower costal margin and anterior superior iliac crest. Waist circumference more than $1020 \mathrm{~mm}$ in case of males and $880 \mathrm{~mm}$ in case of females was considered obesity. ${ }^{10}$ All routine investigations were done in each individual after a 12-hour overnight fast. Baseline thyroid functions ( $\mathrm{FT}_{4}$ and $\mathrm{TSH}$ ) were measured using a commercial immunoradiometric assay (Abbot, North Chicago, USA). Other lab tests include liver function tests, lipid profile, fasting \& two-hour plasma glucose, serum urea \& creatinine, hepatitis B surface (HBsAg) antigen and antibody to hepatitis $C$ virus.

NAFLD was diagnosed as presence of fatty liver by ultrasonography in the absence of excess alcohol intake $(>20$ g/day), medications known to cause fatty liver, seropositivity of hepatitis B surface antigen and antibody to hepatitis C virus.
Ultrasound criteria for Non-alcoholic fatty liver disease ${ }^{11}$ : Fatty liver is seen as bright liver with echogenicity of liver more than that of right kidney.

Grade I: Increased hepatic echogenicity with visible periportal and diaphragmatic echogenicity.

Grade II: Increased hepatic echogenicity with imperceptible periportal echogenicity, without obscuration of diaphragm. Grade III: Increased hepatic echogenicity with imperceptible periportal echogenicity and obscuration of diaphragm.

\section{Statistical Analysis}

The observed data was statistically analysed by using IBMcompatible Statistical Package for the Social Sciences (SPSS) version 20.0. The qualitative data were expressed as numbers (\%) and the comparisons of continuous variables between the two groups were performed with the Student's t-test and categorical variables were compared using the Chi-square test. A p-value of $<0.05$ was considered significant and $p$ value of $<0.001$ was considered highly significant, while $p$ value of $>0.05$ was considered not significant.

\section{RESULTS}

A total 100 hypothyroid cases were included in the study, of which 50 were untreated and 50 were treated. Among untreated hypothyroid cases, 18 (36\%) were between 18-39 yrs., 28 (56\%) were between $40-59$ yrs. and 4 (8\%) were above 60 yrs. of age. In treated group, 18 (36\%) were between 18-39 yrs., 27 (54\%) between $40-59$ yrs. and 5 $(10 \%)$ were above 60 yrs. of age. Majority of hypothyroid cases were between $40-59$ yrs. of age. [Table-1].

\begin{tabular}{|c|c|c|c|c|c|}
\hline \multirow{2}{*}{ Age } & \multicolumn{4}{|c|}{ Hypothyroid Cases } & \multirow{2}{*}{ Total } \\
\cline { 2 - 5 } & $\begin{array}{c}\text { Untreated, } \\
\mathbf{n = 5 0}\end{array}$ & $\mathbf{\%}$ & $\begin{array}{c}\text { Treated, } \\
\mathbf{n = 5 0}\end{array}$ & $\mathbf{\%}$ & \\
\hline $18-39$ yrs. & 18 & 36 & 18 & 36 & 36 \\
\hline $40-59$ yrs. & 28 & 56 & 27 & 54 & 55 \\
\hline$\geq 60$ yrs. & 4 & 8 & 5 & 10 & 9 \\
\hline Total & $\mathbf{5 0}$ & & $\mathbf{5 0}$ & $\mathbf{1 0 0}$ \\
\hline
\end{tabular}

In our study, from 100 hypothyroid cases, 68 (68\%) were male and 32 (32\%) were female. Among untreated hypothyroid cases, $40(80 \%)$ were male and $10(20 \%)$ were female. Among treated hypothyroid cases, 28 (56\%) were male and 22 (44\%) were female. [Table-2].

\begin{tabular}{|c|c|c|c|c|c|}
\hline \multirow{2}{*}{ Gender } & \multicolumn{4}{|c|}{ Hypothyroid Cases } & \multirow{2}{*}{ Total } \\
\cline { 2 - 5 } & $\begin{array}{c}\text { Untreated, } \\
\mathbf{n = 5 0}\end{array}$ & $\mathbf{\%}$ & $\begin{array}{c}\text { Treated, } \\
\mathbf{n = 5 0}\end{array}$ & $\mathbf{\%}$ & \\
\hline Male & 40 & 80 & 28 & 56 & 68 \\
\hline Female & 10 & 20 & 22 & 44 & 32 \\
\hline Total & $\mathbf{5 0}$ & & $\mathbf{5 0}$ & & $\mathbf{1 0 0}$ \\
\hline
\end{tabular}

Table 2. Sex Distribution Study Population

\begin{tabular}{|c|c|c|c|}
\hline Age & $\begin{array}{c}\text { NAFLD } \\
\text { Present }\end{array}$ & $\begin{array}{c}\text { Untreated } \\
\text { Hypothyroid Cases }\end{array}$ & $\mathbf{\%}$ \\
\hline $18-39$ yrs. & 10 & 18 & 55.5 \\
\hline $40-59$ yrs. & 10 & 27 & 37 \\
\hline$\geq 60$ yrs. & 0 & 5 & \\
\hline Total & $\mathbf{2 0}$ & $\mathbf{5 0}$ & $\mathbf{4 0}$ \\
\hline
\end{tabular}

Table 3. Prevalence of NAFLD in Relation to Age Distribution of Untreated Hypothyroid Cases 
PREVALENCE OF NAFLD IN RELATION WITH THE AGE DISTRIBUTION OF UNTREATED HYPOTHYROID CASES

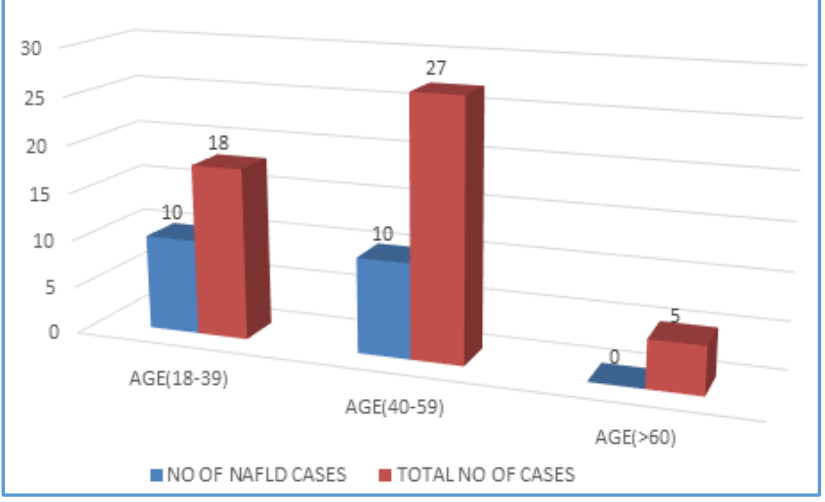

\begin{tabular}{|c|c|c|c|}
\hline Age & $\begin{array}{c}\text { NAFLD } \\
\text { Present }\end{array}$ & $\begin{array}{c}\text { Treated Hypothyroid } \\
\text { Cases }\end{array}$ & $\%$ \\
\hline $18-39$ yrs. & 3 & 18 & 16.6 \\
\hline $40-59$ yrs. & 7 & 28 & 25 \\
\hline$\geq 60$ yrs. & 0 & 4 & \\
\hline Total & $\mathbf{1 0}$ & $\mathbf{5 0}$ & $\mathbf{2 0}$ \\
\hline \multicolumn{4}{|c|}{ Table 4. Prevalence of NAFLD in Relation to Age } \\
Distribution of Treated Hypothyroid Cases \\
\hline
\end{tabular}

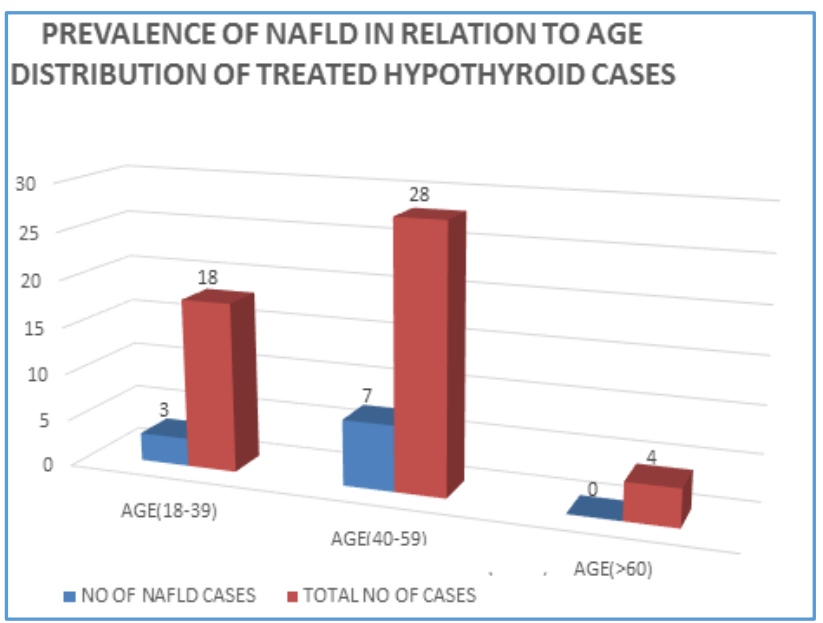

Among 50 untreated hypothyroid cases, 20 NAFLD cases were detected of which 10 (50\%) were between 18-39 yrs., $10(50 \%)$ were between $40-59$ yrs. and no NAFLD cases were detected above 60 yrs. of age. Among 50 treated hypothyroid cases, 10 NAFLD cases were detected of which 3 (30\%) were between $18-39$ yrs., 7 (70\%) were between $40-59$ yrs. and no NAFLD cases were detected above 60 yrs. of age. Out of 100 hypothyroid cases, 30 were having NAFLD of which 20 (40\%) were in the untreated group in comparison to $10(20 \%)$ in treated group. $\mathrm{P}=1.563$ which is statistically insignificant showing no significant relation between age distribution and presence of NAFLD.

\begin{tabular}{|c|c|c|c|}
\hline Gender & $\begin{array}{c}\text { NAFLD } \\
\text { Present }\end{array}$ & $\begin{array}{c}\text { Untreated Hypothyroid } \\
\text { Cases }\end{array}$ & $\mathbf{\%}$ \\
\hline Male & 12 & 28 & 42.8 \\
\hline Female & 8 & 22 & 36.3 \\
\hline Total & $\mathbf{2 0}$ & $\mathbf{5 0}$ & $\mathbf{4 0}$ \\
\hline \multicolumn{2}{|r|}{$\begin{array}{r}\text { Table 5. Presence of NAFLD in Relation to Gender } \\
\text { Distribution of Untreated Hypothyroid Cases }\end{array}$} \\
\hline
\end{tabular}

\begin{tabular}{|c|c|c|c|}
\hline Gender & $\begin{array}{c}\text { NAFLD } \\
\text { Present }\end{array}$ & $\begin{array}{c}\text { Treated Hypothyroid } \\
\text { Cases }\end{array}$ & $\mathbf{\%}$ \\
\hline Male & 7 & 40 & 17.5 \\
\hline Female & 3 & 10 & 30 \\
\hline Total & $\mathbf{1 0}$ & $\mathbf{5 0}$ & $\mathbf{2 0}$ \\
\hline
\end{tabular}

Table 6. Presence of NAFLD in Relation to Gender Distribution of Treated Hypothyroid Cases

Among 50 untreated hypothyroid cases, 20 (40\%) NAFLD cases were detected of which $12(24 \%)$ were male and 8 $(16 \%)$ were female. Among 50 treated hypothyroid cases, 10 (20\%) NAFLD cases were detected of which 7 (14\%) were male and $3(6 \%)$ were female. In our study, NAFLD cases were more prevalent in female population i.e. $34 \%$. $P=0.216$ in untreated hypothyroid cases and $\mathrm{P}=0.781$ in treated hypothyroid cases which is statistically insignificant.

\begin{tabular}{|c|c|c|c|c|c|}
\hline \multirow{2}{*}{ Age } & \multicolumn{3}{|c|}{ USG Grade, n=30 } & \multirow{2}{*}{ Total } & \multirow{2}{*}{$\%$} \\
\cline { 2 - 5 } & Grade-I & Grade-II & Grade-III & & \\
\hline 18-39 yrs. & $2(15.3 \%)$ & $7(53.8 \%)$ & $4(30.7 \%)$ & 13 & 43.3 \\
\hline 40-59 yrs. & $6(35.2 \%)$ & $6(35.2 \%)$ & $5(29.6 \%)$ & 17 & 56.7 \\
\hline Total & $8(26.6 \%)$ & $13(43.3 \%)$ & $9(30.1 \%)$ & 30 & \\
\hline Table 7. Relation of Age with USG Grading of NAFLD, $\boldsymbol{n}=\mathbf{3 0}$ \\
\hline
\end{tabular}

Total 30 NAFLD were detected of which 13 (43.3\%) were between 18-39 yrs., 17 (56.7\%) were between $40-59$ yrs. and no NAFLD case was detected above 60 yrs. of age. Out of these 13 NAFLD cases, 2 (15.3\%) were of USG grade-I, 7 (53.8\%) of USG grade-II and 4 (30.7\%) were of USG grade-III. Among 17 NAFLD cases in age group 40-59 yrs., 6 (35.2\%) were of USG grade-I, 6 (35.2\%) were of USG grade-II and 5 (29.6\%) were of NAFLD USG grade-III. From total 30 NAFLD cases, $8(26.6 \%)$ were of USG grade-I, 13 (43.3\%) were of USG grade-II and $9(30.1 \%)$ were of USG grade-III NAFLD. Out of total NAFLD cases, majority $13(43.3 \%)$ were of USG gradeII. $(\mathrm{P}=1.685)$.

\begin{tabular}{|c|c|c|c|c|c|}
\hline \multirow{2}{*}{ Gender } & \multicolumn{3}{|c|}{ USG Grade, n=30 } & \multirow{2}{*}{ Total } & \multirow{2}{*}{$\%$} \\
\cline { 2 - 4 } & Grade-I & Grade-II & Grade-III & & \\
\hline Male & $5(26.3 \%)$ & $8(42.1 \%)$ & $6(31.6 \%)$ & 19 & 63.3 \\
\hline Female & $3(27.2 \%)$ & $5(45.4 \%)$ & $3(27.2 \%)$ & 11 & 36.7 \\
\hline Total & $\mathbf{8}$ & $\mathbf{1 3}$ & $\mathbf{9}$ & $\mathbf{3 0}$ & \\
\hline \multicolumn{5}{|c|}{ Table 8. Relation of Gender with } \\
USG Grading of NAFLD, $\boldsymbol{n}=\mathbf{3 0}$ \\
\hline
\end{tabular}

Among 30 NAFLD cases, 19 (63.3\%) were male and 11 $(36.7 \%)$ were female. Out of 19 male NAFLD cases, 5 (26.3\%) were of NAFLD USG grade-I, 8 (42.1\%) were of USG grade-II and $6(31.6 \%)$ were of USG grade-III NAFLD. Among 11 female NAFLD cases, 3 (27.2\%) were of USG grade-I, 5 (45.4\%) were of USG grade-II and $3(27.2 \%)$ were of USG grade-III NAFLD. From total 19 male NAFLD cases, 8 (42\%) were of USG grade-II and from 11 female NAFLD cases, 5 $(45 \%)$ were of USG grade-II. ( $\mathrm{P}=0.063)$.

\begin{tabular}{|c|c|c|c|}
\hline TSH (mlU/L) & NAFLD Present & Total & \% \\
\hline$\geq 4.1$ & 27 & 77 & 35 \\
\hline$<4.1$ & 3 & 23 & 13 \\
\hline Total & $\mathbf{3 0}$ & $\mathbf{1 0 0}$ & $\mathbf{3 0}$ \\
\hline \multicolumn{3}{|c|}{ Table 9. NAFLD Distribution in } \\
Relation to Value of TSH, $\mathbf{n = 1 0 0}$ \\
\hline
\end{tabular}




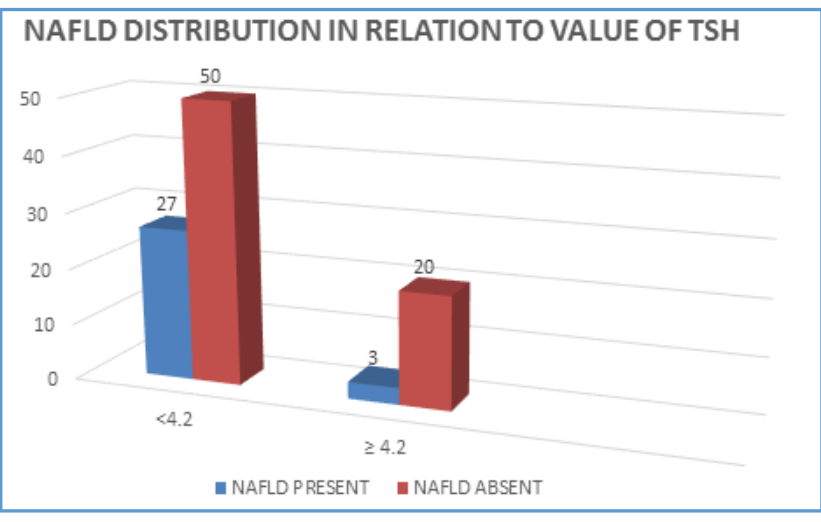

Among 100 hypothyroid cases (treated and untreated), 77 had TSH $\geq 4.1 \mathrm{mIU} / \mathrm{L}$, of which 27 (35\%) had NAFLD, and 23 had TSH $<4.1 \mathrm{mIU} / \mathrm{L}$ of which $3(13 \%)$ had NAFLD. $(p=0.0163)$.

\begin{tabular}{|c|c|c|c|}
\hline FT4 (ng/dL) & NAFLD Present & Total & \% \\
\hline$<0.7$ & 23 & 29 & 79.3 \\
\hline $0.7-1.8$ & 7 & 71 & 9.8 \\
\hline Total & $\mathbf{3 0}$ & $\mathbf{1 0 0}$ & $\mathbf{3 0}$ \\
\hline \multicolumn{3}{|c|}{ Table 10. NAFLD Distribution in } \\
Relation to Value OF T4, $n=100$ \\
\hline
\end{tabular}

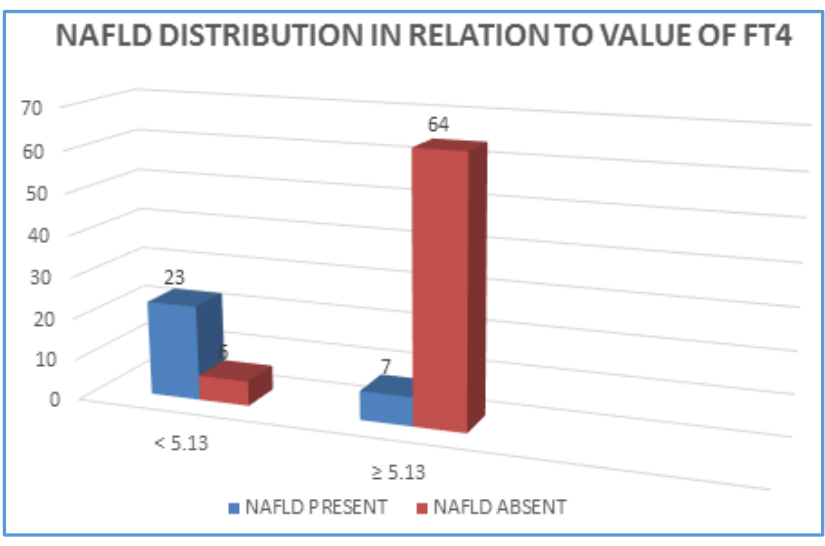

Among 100 hypothyroid cases (treated and untreated), 71 had $\mathrm{FT}_{4}$ between 0.7 to $1.8 \mathrm{ng} / \mathrm{dL}$ of which 7 (9.8\%) had NAFLD, and 29 had $\mathrm{FT}_{4}<0.7 \mathrm{ng} / \mathrm{dL}$, of which 23 (79.3\%) had NAFLD. $(p=0.0238)$.

\begin{tabular}{|c|c|c|c|}
\hline Hypothyroid & NAFLD Present & Total & $\%$ \\
\hline Untreated & 20 & 50 & 40 \\
\hline Treated & 10 & 50 & 20 \\
\hline Total & $\mathbf{3 0}$ & $\mathbf{1 0 0}$ & $\mathbf{3 0}$ \\
\hline \multicolumn{2}{|c|}{ Table 11. Prevalence of NAFLD in Treated } \\
and Untreated Hypothyroid Cases \\
\hline
\end{tabular}

Among 30 cases of NAFLD, 20 were detected in untreated hypothyroid cases and 10 were detected in treated hypothyroid cases. $(\mathrm{p}=0.003)$.

\begin{tabular}{|c|c|c|c|}
\hline & NAFLD Present & Total & \% \\
\hline Case & 30 & 100 & 30 \\
\hline Control & 12 & 100 & 12 \\
\hline \multicolumn{3}{|c|}{ Table 12. Prevalence of NAFLD in } \\
Hypothyroid Cases and Controls \\
\hline
\end{tabular}

Total 30 NAFLD were detected in hypothyroid cases and 12 were detected in control population. $\mathrm{P}=0.003$, which is statistically significant and shows more prevalence of NAFLD in non-obese hypothyroid cases in comparison to age, sex and BMI matched control population.

\section{DISCUSSION}

In our study, 100 non-obese hypothyroid patients were included and USG was done on every patient to detect presence of NAFLD and USG grading of NAFLD was done. These hypothyroid patients were divided in two groups, basing on their treatment status, of which 50 were in treated group and 50 were in untreated group. The results were compared with 100 age, sex and BMI matched non-obese euthyroid control population.

In treated group, maximum number of patients 27 (54\%) belonged to age group of 40-59 years and in untreated group also maximum number of patients $28(56 \%)$ belonged to age group of 40-59 years. Among all hypothyroid cases, 68 (68\%) were male and 32 (32\%) were female. In treated group, 28 (56\%) were male and $22(44 \%)$ were female, whereas in the untreated group $40(80 \%)$ were male and $10(20 \%)$ were female. In a study by Liangpunsakul and Chalasani (2003), the association between thyroid dysfunction and NAFLD have been characterised by relatively small sample and gender imbalance showing female preponderance.12 Mean age of male patients was $45.58 \mathrm{yrs}$. and female was $45.09 \mathrm{yrs}$. which was fairly correlated.

Out of 100 hypothyroid patients, 30 patients had NAFLD of which 20 were in untreated group and 10 in treated group. Study by Marco Bertolotti, Amedeo Lonardo et al demonstrated that prevalence of NAFLD increases with age, ${ }^{13}$ but in our study majority of NAFLD cases i.e. $56.6 \%$ were found in the age group 40-59 yrs., $\mathrm{P}=1.563$ which is statistically insignificant. In our study, out of 30 NAFLD cases, $19(63.3 \%)$ were male and 11 (36.7\%) were female. From 19 male NAFLD cases, majority cases i.e. 8 cases $(42.1 \%)$ were having NAFLD USG grade-II and out of 11 female NAFLD cases, 5 (45.4\%) were having NAFLD USG grade-II. P=0.063, which was statistically insignificant showing no significant relationship between gender \& USG grading of NAFLD. So far as age is concerned, majority NAFLD cases i.e. 17 (56.7\%) were of age group 40-59 yrs. and no NAFLD case was detected above 60 yrs. of age.

In the study group, 77 cases were having TSH $\geq 4.1$ mIU/L, from which 27 (35\%) had NAFLD and rest 23 cases were having TSH $<4.1 \mathrm{mIU} / \mathrm{L}$, of which $3(13 \%)$ had NAFLD. $\mathrm{P}=0.0163$, which is statistically significant, shows increased value of TSH is associated with increased prevalence of NAFLD. In a study by Loria Paola et al regarding endocrine and liver interaction, the role of endocrine pathway in NASH showed that increase in TSH value increases the risk of developing NAFLD. ${ }^{14}$

Among 100 hypothyroid cases, 71 had $\mathrm{FT}_{4}$ between 0.7 to $1.8 \mathrm{ng} / \mathrm{dL}$, of which 7 (9.8\%) had NAFLD and rest 29 had FT4 $<0.7 \mathrm{ng} / \mathrm{dL}$, of which 23 (79.3\%) had NAFLD. $\mathrm{P}=0.0238$, which is statistically significant and shows decreased value of $\mathrm{FT}_{4}$ is associated with more prevalence of NAFLD. Study by Loria Paola et al demonstrated decrease in $\mathrm{FT}_{4}$ increases the risk of developing NAFLD. ${ }^{14}$

Among total 30 cases of NAFLD, 20 were detected in untreated hypothyroid cases and 10 were detected in treated hypothyroid cases. $\mathrm{P}=0.0034$, which was statistically significant, showing more prevalence of NAFLD in untreated hypothyroid patients than treated hypothyroid patients. 
Total 30 NAFLD cases were detected in the study population which is $30 \%$ of total study population and 12 NAFLD cases were detected in control population which is $12 \%$ of total control population. $\mathrm{P}=0.003$, which is statistically significant shows that there is increased prevalence of NAFLD in non-obese hypothyroid patients than age, sex and BMI matched non-obese euthyroid controls.

\section{CONCLUSION}

Our study suggests that prevalence of NAFLD is more in untreated hypothyroid patients. Hypothyroidism is closely associated with NAFLD as an independent risk factor thereby confirming a relevant clinical relationship between these two diseases.

\section{REFERENCES}

[1] Law K, Brunt EM. Non-alcoholic fatty liver diseases. Clin Liver Dis 2010;14(4):591-604.

[2] Angulo P. GI epidemiology: Non-alcoholic fatty liver disease. Aliment Pharmacol Ther 2007;25(8):883-9.

[3] Day CP. Non-alcoholic fatty liver disease: a massive problem. Clin Med (Lond) 2011;11(2):176-8.

[4] Michalaki MA, Vagenakis AG, Leonardou AS, et al. Thyroid functions in humans with morbid obesity. Thyroid 2006;16(1):73-8.

[5] Raftopoulos Y, Gagne DJ, Papasavas P, et al. Improvement of hypothyroidism after laparoscopic Roux-en-Y gastric bypass for morbid obesity. Obes Surg 2004;14(4):509-13.
[6] Pucci E, Chiovato L, Pinchera A. Thyroid and lipid metabolism. Int J Obes Relat Metab Disord 2000;24(Suppl 2):S109-12.

[7] Chung GE, Kim D, Kim W, et al. Non-alcoholic fatty liver disease across the spectrum of hypothyroidism. J Hepatol 2012;57(1):150-6.

[8] Parikh P, Phadke A, Sawant P. Prevalence of hypothyroidism in Non-alcoholic fatty liver disease in patients attending a tertiary hospital in western India. Indian J Gastroenterol 2015;34(2):169-73.

[9] Pagadala MR, Zein CO, Dasarathy S, et al. Prevalence of hypothyroidism in Non-alcoholic fatty liver disease. Dig Dis Sci 2012;57(2):528-34.

[10] Phan-Hug F, Beckmann JS, Jacquemont S. Genetic testing in patients with obesity. Best Pract Res Clin Endocrinol Metab 2012;26(2):133-43.

[11] Lee CH, Choi JW, Kim KA, et al. Usefulness of standard deviation on histogram of ultrasound as a quantitative value for hepatic parenchymal echo texture; preliminary study. Ultrasound Med Biol 2006;32(12):1817-26.

[12] Liangpunsakul S, Chalasani N. Is hypothyroidism a risk factor for non-alcoholic steatohepatitis? J Clin Gastroenterol 2003;37(4):340-3.

[13] Frith J, Day CP, Henderson E, et al. Non-alcoholic fatty liver disease in older people. Gerontology 2009;55(6):607-13.

[14] Loria P, Carulli L, Bertolotti M, et al. Endocrine and liver interaction: the role of endocrine pathways in NASH. Nat Rev Gastroenterol Hepatol 2009;6(4):23647. 